\title{
Civil environmental liability of the government in the French and Iranian legal systems
}

\author{
Fatemeh Jameei:( Fat.jameei.law@iauctb.ac.ir), Ph.D Student in Private Law, Islamic Azad University, Central \\ Tehran Branch, Tehran, Iran \\ Seyed Mohammad Asadi nejad :(asadinezhad@guilan.ac.ir), Associate Prof., department of Law, Faculty of \\ Literature and Humanities, University of Guilan, Rasht, Iran \\ Seyedeh Maryam Asadinejad:(sm.asadinejad@ahrar.ac.ir), Medical doctor, Faculty Member, Law Department \\ ,Ahrar Institute of Technology and Higher Education , Rasht ,Iran \\ Hirad Mokhayeri:( Hiradmokhayeri@gmail.com )Ph.D in International Relations, Political Science Department, \\ Faculty of Humanities, Islamic Azad University, Zanjan Branch, Zanjan, Iran
}

\begin{abstract}
One of the most important issues of the present age is the issue of the environment and understanding its position and importance in human life. However, the importance of this irreplaceable Capital is such that human health is completely tied to its health as a bed of lifetime. However, it can be claimed that in this age, human and natural environment has been exposed to many serious damages. And environmental damage, many of which is virtually irreparable, threatens human life even more. That in case of damage to the environment, On what basis can the loser be held liable; A noteworthy discussion in the present study, Examining the principles of environmental civil liability in the French and Iranian legal systems, we found that both legal systems, While still embracing the traditional theory of environmental civil liability, Over time, and given the shortcomings of this theory, Steps have been taken towards other theories as the basis for this responsibility. Also, the discussion of environmental obligations and civil liability of governments is a fundamental issue in the field of environmental rights. In this research work 'In order to achieve the goals that can be imagined in the field of preserving and supporting this universal gift, it has been examined.
\end{abstract}

Keywords: Environmental Damages, Civil Liability, French Legal System, Iranian Legal System

DOI: $10.7176 / \mathrm{JLPG} / 112-22$

Publication date:August 31st 2021

\section{Introduction}

Undoubtedly, the environment is considered to be the most basic public wealth and the basis for the continuation of human life; But unfortunately in today's societies it is not given the attention it deserves; As far as can be said, Despite increasing scientific advances, The result of today's human encounter With this natural gift, it is at a lower level than in primitive societies. The importance of the issue of the environment is so high that it can be claimed without exaggeration One of the most fundamental challenges of the present century, It is an environmental issue and ways to support it; To the extent that this is no longer a side issue And the countries of the world have introduced it into their political life as a fundamental issue As far as the issue of the right to the environment is concerned Included in all legal texts And is in the category of the third generation of human rights And it can even be claimed Among them occurs in a special place Because human survival is undeniable It depends on the survival of this common human heritage; Therefore, it can be said that the special situation of this right Compared to other rights of this generation, it has been considered as a serious duty to protect and safeguard it. Therefore, since there is always the possibility that not only this task will not be done correctly; But also to take actions contrary to this fundamental duty and lead to serious environmental damage, In the present study, considering that a group of humans around the world live in a common soil called the earth. And this common ground for better management, It is divided into separate sections, each of which is run under the auspices of the government. It will be examined what will be the basis of responsibility in the French and Iranian legal systems if these same states cause damage to the environment. And finally, what civil liability can be imagined for them.

\section{1-Recognizing the right to a healthy environment and its crystallization in laws}

If the Constitutional rights To define the science of reviewing the regulation of powers and guaranteeing rights, guaranteeing the right to a healthy environment based on the second part of this definition is considered a Constitutional right. And various countries have explicitly or implicitly recognized this right by amending or approval new laws. And by incorporating this concept into their constitutions and ordinary laws, they have taken further steps towards preserving and protecting the environment. With this in mind It is necessary to have the right to a healthy environment, In the constitutional and ordinary Law of the two legal systems of France and Iran Let us examine separately. 


\section{1-1- Recognition of the right to a healthy environment in the French legal system}

In French law The introduction of the right to the environment was faced with many ups and downs. In fact, before the year 2005 in France the subject of the environment, It was not explicitly identified at the level of basic norms. The reason was Approximately related to the date of the approval of the constitution and the antiquity of the content of human rights issues. It was only after the approval of the Basic Environmental Charter that This right was explicitly recognized And was able to make a tremendous impact On the French legal system in terms of citizens' enjoyment of a healthy environment. Also in the discussion of recognizing this right "In ordinary French law, At the legislative level for the first time Law of February 2 (1995) Related to strengthening environmental protection In the name of the Barnier Law, the recognition of the right to enjoy a healthy environment As one of the basic principles of environmental protection. Barnier's law was also important in French law in two other ways; First, to declare the elements of the environment as the common heritage of humanity And the second was the public interest in protecting the environment. ${ }^{1}$ In year 2005 this text was included in Articles 2-110 of the French Environmental Code. However, so far its impact on the judicial procedures of this country is not so visible.

\section{1-2-Recognizing the right to a healthy environment in the Iranian legal system}

In Iranian law, Before the Islamic Revolution and also in the Constitutionalism And in its complement, There was no specific reference to the issue of the environment and the citizens' enjoyment of a healthy environment. Because basically the right to the environment, It was not relevant at that time. Only with the victory of the Islamic Revolution And it was clearly with the approval of Article 50 of the Constitution that The issue of having a healthy environment By consensus of members of constitutional experts And approved without objection, The way it is written, the content and the requirements of this principle illuminate one of the most advanced environmental principles in the constitution. In addition, in Article 3 of the Constitution law, various elements of the environment were introduced as public wealth, which should be used in the public interest. Regarding the inclusion of this right in the ordinary laws of Iran, it should be said that the issue of citizens' enjoyment of the right to a healthy environment has not been explicitly identified in the ordinary laws and regulations; However, this lack of explicit recognition does not mean that there are no laws and regulations to guarantee the citizens' enjoyment of this right. In addition to guaranteeing this right In the traditional rules based on Islamic jurisprudence, such as the rule of no damage, prohibition of corruption, development and prosperity, Numerous laws and regulations related to the right to a healthy environment have beenpassed before and after the Islamic Revolution. ${ }^{2}$

By recognizing the right to a healthy environment in the laws and regulations of the French and Iranian legal systems, In the event of damage to the environment that results in the violation of this fundamental right, environmental civil liability will be borne by the cause of the damage.

\section{2- Theoretical foundations of environmental civil liability}

In stating that On what basis can environmental damage be held liable? Is anyone responsible for harming the environment illegally and committing a fault or no fault? And what environmental environmental liability is based on. There is disagreement among Lawyer and various principles have been proposed in this regard. Some have accepted the emergence of environmental civil liability on the basis of fault and some on the basis of danger, some on the basis of absolute and some on the basis of the theory of guarantee of rights and so on.

\section{2-1-Theory of fault}

This theory is the most traditional theory in environmental civil liability. Accordingly, environmental damages can not be claimed unless the fault of the cause of the damage can be proven. Therefore, the injured party will be liable if he can prove that the perpetrator was at fault. ${ }^{3}$ It should be noted that there is disagreement about what is the criterion for determining the fault in environmental damage. Some use personal criteria and some use some subjective criteria. When to fauil, We mean Imprudent or carelessness. It should be seen that when environmental damage occurs, harmful Imprudent is the criterion for the occurrence of fault. Or that the cause of the environmental damage has taken the necessary precautions, but because of the fact that this act was committed by people،It is far from expected, this act is considered a fault. If we accept the first criterion, we believe in a personal criterion, and if we accept the second criterion, we believe typical criterion. Examining the theories, it is concluded that the criterion is a typical accepted by lawyers and judicial opinions, which, of course,

1- Mashhadi, Ali (2013), The Right to a Healthy Environment (Iranian-French Model), First Edition, Tehran: Mizan Publications. p-p 78 
brings us closer to the choice of absolute responsibility in the category of environmental degradation. ${ }^{1}$ It should be noted that due to the specific nature of environmental damage and sometimes the existence of multiple detriments and problems related to proving the causal relationship, it is difficult to prove fault in environmental damage. ${ }^{2}$ Compensation for many of the environmental damage seems to be difficult or even impossible in this theory.

\section{2-2-The theory of pure responsibility (absolute responsibility)}

In some cases, attributing fault to the cause of damage is a difficult task and sometimes it is not possible, for example in cases such as violation of environmental rights or unauthorized use of it, It is better to no longer need to prove guilt and be held responsible for the loss. ${ }^{3}$ Absolute responsibility means that responsibility for the existence or non-existence of guilt is absolute; That is, in the case of environmental damage, the person is held liable if there is fault or no fault, Unless he proves his innocence; That is, if the person who harms the environment proves that the environmental damage caused by the Cairo area, for example, was due to a celestial disaster, he will be released from responsibility. ${ }^{4}$ Therefore, the imposition of the task of compensating the environmental damage on the importer in this theory is possible only by proving the attribution of the damage to the cause of the damage and there is no need to prove the fault on his part. Therefore, there is no need to prove the fault and the compensation for the environmental damage can be based on the harmful burden, regardless of the realization.

\section{2-3-Risk theory}

Risk theory Based on no fault It indicates this in this theory, only the occurrence of damage and its relationship with the cause of damage should be proven and there is no need to prove fault. Every person is obliged to bear the possible loss of his action based on external responsibility, whether due to fault or without fault. ${ }^{5}$ Risk theory has been proposed in two different ways:

\section{2-3-1-Risk-benefit theory}

According to the risk-benefit theory, anyone who engages in an activity and benefits from it and creates a dangerous environment for others, the person who benefits from this environment must compensate for its losses .$^{6}$ This theory of environmental damage is defined as compensating for environmental damage if the offender has committed a beneficial act and caused damage to the environment. But there is a serious criticism of this theory; If a person does not benefit from his activity, there is no compensation. For example, if someone gets in their car and is driving on a road and causes damage to the environment, they should not be held responsible.

\section{2-3-2-Activity risk theory (absolute risk)}

Contrary to the risk-benefit theory, this theory states that whoever is active, whether this activity is for-profit or non-profit, It must compensate the damage caused by its activity.$^{7}$ It seems that although there is an objection to this theory, such as restricting the activities of individuals; But it has paved the way for resolving the objection to the risk-benefit theory. Therefore, in the case of environmental civil liability based on the theory of danger, there is no need to prove The injured person fault; Rather, as soon as a person engages in an activity that benefits him and leads to damage to the environment, he is responsible and must compensate, whether he is at fault or not . The injured person to the environment According to this theory, there is an objective responsibility for environmental damage. This theory has been criticized from various economic (activity risk) and social (reducing the motivation of individuals in society) aspects. In particular, it has been criticized for restricting economic and industrial activities and high-risk activities, and in some cases, the application of this theory also appears to be against judicial fairness.$^{8}$ Despite all the drawbacks, it seems that this theory can play an important role in compensating for environmental damage and protecting the environment.

\footnotetext{
4- Fahimi, Azizullah (2012), Civil Liability Due to Environmental Destruction in Iranian Jurisprudence and Law (Comparative Study in French Law and International Documents), First Edition, Qom: Institute of Islamic Sciences and Culture, p-p 341-342. 5- Babaei Moghadam, Abedin (2005), "Study of the differences between environmental damage and other damages", Master of Environmental Law, Faculty of Law, Shahid Beheshti University: Tehran, p-p 78 6- Badini, Hassan (2005), Philosophy of Civil Liability, First Edition, Tehran: Justice Publications, p-p 326. 7- Katozian, Nasser (2003), Non-Contractual Obligations, Coercive Guarantee, two volumes, third edition, Tehran: University of Tehran Press, p-p 530. 5 - Fahimi, Azizullah (2012), Civil Liability Due to Environmental Destruction in Iranian Jurisprudence and Law (Comparative Study in French Law and International Documents), First Edition, Qom: Institute of Islamic Sciences and Culture, p-p 345.

9- Katozian, Nasser (1992), Legal Events, First Edition, Tehran: Yalda Publications, p-p 160-162.

7 - Fahimi, Azizullah (2012), Civil Liability Due to Environmental Destruction in Iranian Jurisprudence and Law (Comparative Study in French Law and International Documents), First Edition, Qom: Institute of Islamic Sciences and Culture, p-p 347.

11- Bahrami Ahmadi, Hamid and Fahimi, Azizullah (2007), "Fundamentals of Environmental Civil Liability in Iranian Jurisprudence and Law", Islamic Studies and Law, Volume 8 , 


\section{2-4-Mixed theories}

The two theories of guilt and risk are theories of interest in the field of environmental law, but given the drawbacks that exist in each of these theories, In order to balance and establish a relationship between the two theories, intermediate theories are presented.

\section{2-4-1-Theory of fault assumption}

This theory is in fact a modification of the two theories of fault and risk. In the sense that it has neither the difficulty of proving the theory of guilt nor the ease of the theory of risk. In this theory, the basis of fault is accepted with a fundamental adjustment. In this way, it is assumed that the cause of the environmental damage is to blame, but it must be provided with evidence. Get rid of this responsibility. In fact, the internal logic of the theory of the presumption of fault indicates the displacement of the claimant and the denier; That is, in the position of proving guilt, for example, it is not the victim of pollution who must prove the harm of the victim, Rather, it is the polluter who must prove his innocence and absolve himself of responsibility . ${ }^{1}$ Therefore, given that in some cases, such as the environmental debate, proving the causal relationship between the injurious and the injurious is difficult and may not even be possible in some cases, According to this theory, fault is the cause of the presumed loss and it is assumed that he is at fault. A person can be absolved of responsibility by proving that the loss was in the Cairo area, but assuming responsibility is not possible. ${ }^{2}$ Based on this, it can be concluded that in this theory, it is assumed that the harmful environmental has committed a fault. Unless it provides a reason and proves that it did not play a role in causing the damage, then in this theory the principle is to protect the environment.

\section{2-4-2-Unconventional work theory}

According to this theory, an unusual act gives rise to liability for environmental damage. Therefore, if a conventional or so-called "permissible" jurisprudential action is taken and as a result of this action, environmental damage is caused, A person will be sentenced to compensation only if proven guilty. This theory has been widely criticized; Including what is meant by unconventional work? If we say that unconventional work is another interpretation of negligence, In fact, this theory will be nothing but a repetition of the theory of fault ${ }^{3}$ Based on what has been said, if the occurrence of liability for the injured person is based on the theory of work is unusual, The condition for establishing responsibility on her is that the act performed is unconventional Therefore, it can be objected that if damage is done to the environment, but it causes normal work. Harmful to the environment will not be responsible.

\section{2-4-3-Theory of responsibility for dangerous objects}

In this theory, the emphasis is on the type of activity. This theory is also a supportive theory in the field of environmental damage. Accordingly, a person who uses dangerous and harmful objects is guaranteed against damage to the environment. For example, chemical producers, polluting industrial plants and the like will have absolute responsibility according to this theory. ${ }^{4}$ Therefore, according to this theory, proving guilt in the occurrence of liability for the person causing the environmental damage is not necessary.

\section{2-4-4-Theory of guarantee of right}

This theory was proposed by the famous French jurist Boris Starck. Unlike proponents of the fault and risk theory, he focused on lost benefits instead of evaluating harmful work. Starck's analysis is influenced by the school of individual originality and is based on the defense of individual rights. This theory obliges others to ensure respect for the safety, health, life and rights of others. And it is on this basis that Starck gives freedom the right of precedence in the struggle between freedom and civil liability. Therefore, based on this theory, it can be said that in order to ensure respect for the right to health, the right to life and the right to the environment, If a person harms the environment, he is responsible for compensation, even if he is not at fault.$^{5}$ The founder of this theory seems to have considered the mission of rules and regulations to protect such rights, which include environmental rights. And provide a proper enforcement guarantee for its aggressors. This guarantee of implementation in the environmental debate is the same as the compensation for the environmental damage caused by the damage. And the loss-making duty is to compensate for the legal guarantees we have enumerated, which include the right to enjoy a healthy environment. And the one who is harmful to the environment is

\footnotetext{
2- Katozian, Nasser (2003), Non-Contractual Obligations, Coercive Guarantee, two volumes, third edition, Tehran: University of Tehran Press, p-p 542.

3 - Bahrami Ahmadi, Hamid and Fahimi, Azizullah (2007), "Fundamentals of Environmental Civil Liability in Iranian Jurisprudence and Law", Islamic Studies and Law, Volume 8, Number 2, p. 121-150

4 -Ibide, 2007

5 - Qasemzadeh, Seyed Morteza (2004), Principles of Civil Liability, Second Edition, Tehran: Mizan Publications, p-p 216.
} 
responsible for guaranteeing this right and is obliged to compensate the environmental damage. ${ }^{1}$

Based on the studies conducted, mixed theories are a combination of fault theory and hazard theory; But it should be examined what kind of responsibility is accepted based on the existing conditions; That is, to base one of these two theories on mixed theory, Consider the principle the theory of fault and, exceptionally, the theory of danger, or vice versa.

\section{3- The basis of environmental civil liability in the French legal system}

Adequate identification of the basis of a regime that provides civil liability for environmental damage is a problem faced by the projects that the regime is establishing; Despite numerous conventions for the protection of the environment, none of the drafts, Does not clearly state the basis of environmental civil liability ${ }^{2}$; However, regarding the basis of civil liability in the French legal system, it should be said that the theory of fault is the common approach in the civil liability regime of most legal systems such as France. It is far from the principles and philosophy of environmental law. According to Articles 2003 and 2004 of the French Civil Code, a claim for damages and holding the perpetrator liable is subject to proof of the perpetrator's guilt. Since in French environmental law and according to paragraph 1 of Article 1384 of the Civil Code in one case, liability without proving guilt is considered for the cause of the damage And it is about dangerous objects that cause damage other than machines and industrial factories. ${ }^{3}$ Now, if we accept that the meaning of "other" in the above explanation also includes the environment, it can be concluded that in the French legal system, the theory of liability for dangerous objects has been considered as the basis of environmental civil liability. But it must be said that the mere existence of this example is not enough to accept that the basis of this liability in French law is, in fact, the theory of liability for dangerous objects. The theory of the guarantee of rights also seems to have been debated for the first time in France. However, according to studies, this theory is not recognized as the basis of environmental civil liability in the French legal system. Reflecting on what is really the basis of environmental civil liability in the French legal system, In Italy, Spain, the United Kingdom and the Netherlands, traditional civil liability laws continue to apply. However, in the French legal system, pure (absolute) liability for some environmental pollutants is accepted as the basis. In other pollutions, fault-based liability is followed. ${ }^{4}$

\section{4-The basis of civil liability resulting from environmental degradation in the Iranian legal system}

The most common approach in the Iranian civil liability regime is the theory of fault. However, studies show that although the basic principle accepted for the basis of civil liability is liability based on fault, This basis does not meet the needs of today's society in terms of compensation for environmental damage. In this regard, in the Iranian legal system, the basis of civil liability resulting from environmental degradation has sometimes approached the theory of guarantee of rights. For example, one of the jurists in order to protect the rights and freedoms of work has ruled that: "If flames are thrown from a blacksmith shop and burn the clothes of passersby, the blacksmith is not responsible; Because the requirement of his blacksmithing profession is throwing fire" ${ }^{5}$ In Iranian law, the legislator, by creating joint and several liability of usurpers in good faith along with the main usurper and wasteful of other property, does not think except to eliminate the loss of the owner and in order to guarantee the interests of the owner, has legislated . ${ }^{6}$ It should be noted that jurists have considered different rights; If we say that respect for the right is what they want, this respect for the right confirms the theory of guarantee of the right. It also seems that the purpose of some Iranian laws, such as the law on liability in traffic accidents, is to guarantee the lost right. Although in the Iranian legal system, the theory of guaranteeing the right in the direction of environmental damages has been considered, but still this theory can not be considered as the real basis of environmental civil liability in the Iranian legal system. Therefore, with the help of laws and regulations, such as Article 50 of the Constitution, in which the protection of the environment is considered a public duty. And prohibits any economic activity other than that that pollutes the environment or causes irreparable damage. As the theory of fault can be considered as the basis of environmental civil liability, He also accepted liability without proof of guilt (absolute liability) as a basis for this civil liability in environmental law.

\section{5- The position of the government in preserving the environment}

Governments are responsible for the environment as the lifeblood of their citizens and have commitments to

\footnotetext{
1 - Qasemzadeh, Seyed Morteza (2011), Requirements and Civil Liability without a Contract, Ninth Edition, Tehran: Mizan Publications, p-p 39.

2 - Khoeini, Ghafoor et al. (2015), "Civil Liability for the Overseas Transfer of Hazardous Waste and its Disposal in Iranian Law and the 1999 Additional Protocol to the Basel Convention”, Quarterly Journal of Private Law Research, Volume 3, Number 10, p-p 67-100.

3 - Prieur, Miechel. (2004). Droit de l'environnement, Paris: Dalloz. 5 ed, p-p 916.

4 - Katozian, Nasser and Ansari, Mehdi (2008), "Liability for Environmental Damage", Law Journal Quarterly Law and Political Science, Volume 38, Number 2, p. 285-313.

5 - Qasemzadeh, Seyed Morteza (2004), Principles of Civil Liability, Second Edition, Tehran: Mizan Publications, p-p- 302.

6 - Katozian, Nasser (2003), Non-Contractual Obligations, Coercive Guarantee, two volumes, third edition, Tehran: University of Tehran Press, p-p 531-532.
} 
preserve and protect it. In such a way that acting outside of its obligations in a way that leads to damage to the environment has environmental civil liability, which is discussed below.

\section{5-1- Governments' commitments to the environment}

Governments' commitment to environmental protection means their commitment to refrain from polluting areas outside their jurisdiction. Governments can achieve their environmental goals by planning and legislating. In order to explain this, we can refer to documents such as the resolution of December 14, 1990, the UN General Assembly as the need to ensure a healthy environment for the well-being of every individual. Which were essential in declaring, approving, establishing and defining the framework and content of the right to the environment. In fact, member states are committed to promoting the protection and improvement of the environment and to encouraging public participation through measures such as providing environmental information to the public. At present, at the domestic level, approximately 4 countries, in order to recognize the right to a healthy environment, have included standards in their laws that require governments to guarantee a healthy environment for citizens. ${ }^{1}$ Today, we clearly see that environmental issues have entered a fundamental part of the agenda of governments. In this regard, environmental law thinkers have developed rules to explain the obligations of governments. Since the role of a healthy environment in human life is an undeniable necessity, Governments are committed to these commitments.

\section{5-2- Environmental civil liability of the government}

Civil liability for environmental encroachment has a long history in the European Union. There are special laws on civil liability for environmental damage in some EU countries, such as Germany, Finland, Sweden and Denmark. And in others, such as France, Italy, the United Kingdom, and the Netherlands, the same traditional rules of civil liability apply to compensation. Due to the fact that net environmental damages cannot be claimed under civil law and liability, many countries have specific laws on environmental encroachment. Also, the basis of civil liability for environmental damage in the rights of most EU countries has changed over time to pure liability. In 1993, the European Commission published its basic views on civil liability for environmental damage . ${ }^{2}$ It should be noted that in general, liability for environmental damage is one of the most important concepts that regulate relations between states and is the principle of sovereignty of states and needs to be considered in the cross-border debate. According to this principle, states are free to use their natural resources within their own territory to the extent that they do not interfere with the similar rights of other states in this regard. Therefore, the principle of sovereignty of states guarantees the right to independent exploitation of their existing natural resources and also the right not to invade the land of others; Therefore, if government activity leads to transboundary environmental damage or the risk of such damage, the government will be questioned. It is difficult to take responsibility for environmental wrongdoing; Because either the amount of damage is not significant Or that the rules relating to pure liability with liability have not been properly complied with. Under traditional law, governments are usually not directly responsible for such acts unless they have been shown to be committed to controlling the dangerous activities of individuals within their jurisdiction. But they have failed; However, due to industrialization and the increasing risks of transboundary environmental damage, there is an increasing need to create special rules that are precisely applicable and include effectiveness. A state's violation of basic environmental rules is a precondition for the injured state's right to compensation. If this violation is proven, the offending government is obliged to compensate the damage and otherwise it is not obliged to compensate anything. ${ }^{3}$ Therefore, in general, the environmental civil liability of the government can be considered in the fact that if the environmental damage is attributed to the action of the government, or the government commits an illegal act And this action causes damage to the environment, civil liability imposed on him can be applied in various ways such as issuing an interim injunction, considering punishment against the government, and so on.

\section{5-2-1-Issuance of temporary order on environmental damages}

Since compensation for environmental damage often cannot restore the status quo ante, Actions that are likely to harm the environment must be avoided. Temporary order is one of the solutions that can reduce pollution or other environmental damage. This solution is usually issued out of turn after assessing the irreparable damage and threat to public health; Therefore, in environmental cases where immediate action is needed, it seems appropriate for both individuals and governments. Where the government is at a disadvantage, an interim

\footnotetext{
1 - Ramesht, Mohammad Hossein (1996), Application of Geomorphology in National, Regional and Economic Planning, Tourism, First Edition, Isfahan: Isfahan University Press, 1996. P-p 142-143.

2 - European Commission. (2000). White paper on Environmental liability, available at https://ec.europa.eu/environment/legal/liability/pdf/el full.pdf.

3 - Taghizadeh Ansari, Mostafa (1995), Environmental Law in Iran, First Edition, Tehran: Samat Publications, P-p 30-31.
} 
injunction may be issued against the government. Since the issuance of an interim injunction is important in environmental matters, for example, we can refer to the directive issued by the judiciary to the courts throughout the country, which states: "Considering the protection of Anfal and public wealth, including forests, pastures, natural forests, seas, lakes and rivers, and the protection of the environment in accordance with Articles 45 and 50 of the Constitution are among the duties of the government. And any kind of activity, whether economic or otherwise, that causes the destruction of forests and pastures and the pollution of inland waters and the destruction of the environment, is prohibited... In accordance with the files and complaints of the Departments of Natural Resources, Environment, Health and other relevant institutions, the heads of the judiciary shall appoint one or more special branches for this purpose and the said branches shall be obliged to stop To issue the stay of the aggressor operation until a final verdict is issued ..." . In another example, we can refer to Note 11 of the Law on Environmental Protection and Improvement, which provides: "The head of the organization may, without prior notice, order to prevent the continuation of their work and activities in the case of resources and factors that pose immediate risks."

\section{5-2-2-Imposition of punishment for environmental damages}

The purpose of environmental punishment is to express the community's opposition to prohibited behavior and to send a deterrent message to stop similar behavior. In this regard, it can be said that some courts have imposed financial penalties for violating environmental rights against governments. The litigants argued that the government should be exempt from financial punishment; Because paying the fine will do nothing but transfer money from one part of the government to another. However, in the opinion of the court, this neglect of the environment should not be underestimated and makes the government responsible for the protection of species and the environment. ${ }^{2}$ Therefore, imposing sanctions for environmental damage can have a deterrent effect on both individuals and the government. And prevent the recurrence of destructive environmental acts and reduce the rate of such crimes.

\section{Conclusion:}

According to the present study, the right to a healthy environment is one of the issues related to new human needs. And its purpose can be considered the protection of nature and its resources, the fight against pollution and pests, and in general the recognition of this right and the effort to preserve the health of this public wealth for the world and future generations. In this regard, since the environment is exposed to more and more serious dangers every day, and the inadequacy and inadequacy of the current laws does not place the responsibility on the destroyers of the environment as it should be. And is unable to prevent widespread attacks on public natural resources, seeking to find an acceptable environmental civil liability that is most effective in protecting the environment. Examining it in the two legal systems of France and Iran, we came to the conclusion that none of the theories proposed as a basis can fully compensate for environmental damage. However, according to the law in these two legal systems, there are traces of the traditional theory of fault as the basis of environmental civil liability in the French legal system. However, due to some shortcomings in this theory, over time, this basis has changed and today in most cases pure (absolute) responsibility has replaced it. Also in the Iranian legal system, like the French legal system, while the traditional theory of fault remains as a basis for environmental civil liability; In case of some damages in which it is not possible to find fault, liability can be accepted as proof of this liability without proving fault (absolute liability). It should be noted that liability for environmental damage is effective even in relations between governments. And States are free to use the natural resources of their territories to the extent that they do not conflict with the similar rights of other States. And in the event of environmental damage by them, in the legal systems of most countries such as France and Iran, while the traditional rules of civil liability resulting from compensation are still announced, the rules of pure liability also prevail. Finally, to get rid of the environmental problem that is affecting the whole world in the present age and threatening human life and natural species more and more; In case of damage to the environment, it is recommended to try to compensate the damage as soon as possible and in the best way to compensate for the damage that led to the damage to the environment or reduce it to a minimum. It is also possible to play an effective role in preventing the occurrence of damage by enacting basic laws in the harmful obligation to compensate for environmental damage; For example, given that the traditional view of liability for environmental damage considers the liability of governments after environmental damage has occurred, It set tasks for governments to determine their responsibilities before pollution and damage occur, and to have a deterrent aspect.

1 - Bahrami Ahmadi, Hamid and Alamkhani, Azam (2013), "Reflections on the Practical Aspects of Civil Liability Claims Against the Government in Relation to Environmental Damages", Public Law Knowledge Quarterly, Volume 2, Number 5, p. 83-102.

2 - Ibide, 2013 


\section{References}

1-Babaei Moghadam, Abedin (2005), "Study of the differences between environmental damage and other damages", Master of Environmental Law, Faculty of Law, Shahid Beheshti University: Tehran.

2-Badini, Hassan (2005), Philosophy of Civil Liability, First Edition, Tehran: Justice Publications.

3-Bahrami Ahmadi, Hamid and Fahimi, Azizullah (2007), "Fundamentals of Environmental Civil Liability in Iranian Jurisprudence and Law", Islamic Studies and Law, Volume 8, Number 2, pp. 121-150.

4-Bahrami Ahmadi, Hamid and Alamkhani, Azam (2013), "Reflections on the Practical Aspects of Civil Liability Claims Against the Government in Relation to Environmental Damages", Public Law Knowledge Quarterly, Volume 2, Number 5, pp. 83-102.

5-Taghizadeh Ansari, Mostafa (1995), Environmental Law in Iran, First Edition, Tehran: Samat Publications. 6-Khoeini, Ghafoor et al. (2015), "Civil Liability for the Overseas Transfer of Hazardous Waste and its Disposal in Iranian Law and the 1999 Additional Protocol to the Basel Convention”, Quarterly Journal of Private Law Research, Volume 3, Number 10, pp. 67-100.

7-Ramesht, Mohammad Hossein (1996), Application of Geomorphology in National, Regional and Economic Planning, Tourism, First Edition, Isfahan: Isfahan University Press, 1996.

8-Fahimi, Azizullah (2012), Civil Liability Due to Environmental Destruction in Iranian Jurisprudence and Law (Comparative Study in French Law and International Documents), First Edition, Qom: Institute of Islamic Sciences and Culture.

9-Qasemzadeh, Seyed Morteza (2004), Principles of Civil Liability, Second Edition, Tehran: Mizan Publications.

10-Qasemzadeh, Seyed Morteza (2011), Requirements and Civil Liability without a Contract, Ninth Edition, Tehran: Mizan Publications.

11-Katozian, Nasser (1992), Legal Events, First Edition, Tehran: Yalda Publications.

12-Katozian, Nasser (2003), Non-Contractual Obligations, Coercive Guarantee, two volumes, third edition, Tehran: University of Tehran Press.

13-Katozian, Nasser and Ansari, Mehdi (2008), "Liability for Environmental Damage”, Law Journal Quarterly Law and Political Science, Volume 38, Number 2, pp. 285-313.

14-Mashhadi, Ali (2013), The Right to a Healthy Environment (Iranian-French Model), First Edition, Tehran: Mizan Publications.

15-European Commission. (2000). White paper on Environmental liability, at-http, eur-lex Europa.

16- Prieur, Miechel. (2004). Droit de l'environnement, Paris: Dalloz. 